\title{
Higher IQ in childhood is linked to a longer life
}

\author{
(c) $\mathbb{( 1 ) \Theta}$ OPEN ACCESS \\ New data on cause of death suggest the link is mediated by risk factors such as smoking
}

Daniel Falkstedt assistant professor ${ }^{1}$, Anton C J Lager head of unit ${ }^{2}$

${ }^{1}$ Department of Public Health Sciences, Karolinska Institutet, Stockholm, Sweden; ${ }^{2}$ Surveillance and Analysis, Centre for Epidemiology and Community Medicine, Stockholm, Sweden

The association between intelligence level (IQ) measured during childhood or adolescence and longevity has been observed in many studies. It is clear that, on average, individuals with higher IQs have tended to live a little longer than those with lower IQs. A limitation in the evidence base so far, however, has been an over-reliance on studies of male conscripts followed up only to middle adulthood.

In a linked paper (doi:10.1136/bmj.j2708), Calvin and colleagues now report findings from the first study of a whole population birth cohort linking intelligence test scores from age 11 among girls and boys born in Scotland in 1936 to 68 years of data on cause of death. ${ }^{1}$ They found that higher IQ scores in this cohort were associated with lower rates of death until age 79, including deaths from coronary heart disease, stroke, cancer, respiratory disease, digestive disease, external causes of death, and dementia. The associations were largely similar in women and men, with the exception of suicide, which was not associated with IQ in women.

New in this study is the uniquely comprehensive follow-up of major causes of death through to an age at which almost half of the participants had died. By going beyond studies of all cause mortality, ${ }^{23}$ these authors are able to illuminate an otherwise hard to interpret association between early intelligence and subsequent risk of death. Importantly, they report associations between childhood IQ and mortality from 15 different types of cancer.

One idea underlying this research is that the association between intelligence and mortality can be attributed to genetic differences. ${ }^{4}$ This is different from the common perception among social epidemiologists ${ }^{56}$ that higher intelligence is associated with success in the educational system and with favourable environmental conditions and lifestyles (a culture of non-smoking, for example) linked to better education, work, and income, and, in addition, that higher intelligence can help people to recognise and deal with daily risks such as traffic. Instead, the genetic idea states that an individual's IQ might signal individual differences in bodily "system integrity" and resilience $^{7}$ and, ultimately, individual differences in longevity.
Calvin and colleagues' extensive analyses linking childhood IQ and later mortality from different causes, including types of cancer, should be viewed against this background, and the authors discuss at length how their findings could be interpreted. ${ }^{1}$ A close look at their figure 2 is particularly enlightening. Here, the authors report associations between IQ in childhood and cause specific mortality per 10th (or quarter) of test grade, analogous to incremental risk per dose of exposure.The most obvious dose-response relations are those for cardiovascular disease, coronary heart disease, stroke, smoking related cancer, and respiratory disease. Injuries could also be added to this list. Even so, the pattern in figure 2 tells us that lifestyle, and especially tobacco smoking, must be an important component in the effect of intelligence on differences in mortality.

The authors explored this interpretation further in subanalyses of a smaller dataset. Significant associations between IQ and smoking related causes of death still remained after adjustment for smoking status and occupational class in adulthood, suggesting that these factors did not fully account for mortality differences. These findings are inconsistent, however, with those from two previous studies that also controlled for tobacco consumption, social position, and other risk factors. ${ }^{89}$ Furthermore, differences in risk factors such as smoking are often underestimated, and this methodological limitation along with others can lead to associations remaining spuriously significant after statistical adjustments. ${ }^{10}$ Although the authors discuss this possibility, the limitation becomes clear when they report that associations between IQ and mortality from smoking related cancer, including lung cancer, were only partially attenuated after adjustment for smoking. In a flawless dataset, we would expect these associations to disappear completely after adjustment.

Calvin and colleagues' study is the largest to date reporting causes of death across the life course, and it provides us with interesting results. ${ }^{1}$ The study confirms that intelligence test scores in childhood are significantly associated with subsequent mortality. Importantly, it shows that childhood IQ is strongly associated with causes of death that are, to a great extent, 
dependent on already known risk factors. Tobacco smoking and its distribution along the socioeconomic spectrum could be of particular importance here. It remains to be seen if this is the full story or if IQ signals something deeper, and possibly genetic, in its relation to longevity.

Competing interests: We have read and understood the BMJ Group policy on declaration of interests and declare the following interests: None.

Provenance and peer review: Commissioned, not peer reviewed.

1 Calvin CM, Batty GD, Der G. Childhood intelligence in relation to major causes of death in 68 year follow-up: prospective population study. BMJ 2017;357::2708.

2 Calvin CM, Deary IJ, Fenton C. Intelligence in youth and all-cause-mortality: systematic review with meta-analysis. Int J Epidemiol 2011;40:626-44. doi:10.1093/ije/dyq19021037248

3 Čukić I, Brett CE, Calvin CM, Batty GD, Deary IJ. Childhood IQ and survival to 79: Follow-up of $94 \%$ of the Scottish Mental Survey 1947. Intelligence 2017:63:45-50doi:10.1016/j.intell.2017.05.002.

4 Arden R, Luciano M, Deary IJ. The association between intelligence and lifespan is mostly genetic. Int J Epidemiol 2016;45:178-85. doi:10.1093/ije/dyv11226213105
5 Lager $\mathrm{A}$, Bremberg $\mathrm{S}$, Vågerö $\mathrm{D}$. The association of early IQ and education with mortality: 65 year longitudinal study in Malmö, Sweden. BMJ 2009;339:b5282. doi:10.1136/bmi.b528220008007

6 Link BG, Phelan JC, Miech R, Westin EL. The resources that matter: fundamental social causes of health disparities and the challenge of intelligence. $J$ Health Soc Behav 2008;49:72-91. doi:10.1177/00221465080490010618418986

7 Deary IJ. Looking for 'system integrity' in cognitive epidemiology. Gerontology 2012:58:545-53 doi:10.1159/00034115722907506

8 Hemmingsson T, Melin B, Allebeck P, Lundberg I. Cognitive ability in adolescence and mortality in middle age: a prospective life course study. $J$ Epidemiol Community Health 2009;63:697-702. doi:10.1136/jech.2008.07916019574248

9 Hemmingsson T, v Essen J, Melin B, Allebeck P, Lundberg I. The association between cognitive ability measured at ages $18-20$ and coronary heart disease in middle age among men: a prospective study using the Swedish 1969 conscription cohort. Soc Sci Med 2007;65:1410-9. doi:10.1016/..socscimed.2007.05.00617582667

10 Canto JG, Iskandrian AE. Major risk factors for cardiovascular disease: debunking the "only 50\%" myth. JAMA 2003;290:947-9. doi:10.1001/jama.290.7.94712928473

Published by the BMJ Publishing Group Limited. For permission to use (where not already granted under a licence) please go to http://group.bmj.com/group/rights-licensing/ permissionsThis is an Open Access article distributed in accordance with the Creative Commons Attribution Non Commercial (CC BY-NC 4.0) license, which permits others to distribute, remix, adapt, build upon this work non-commercially, and license their derivative works on different terms, provided the original work is properly cited and the use is non-commercial. See: http://creativecommons.org/licenses/by-nc/4.0/. 